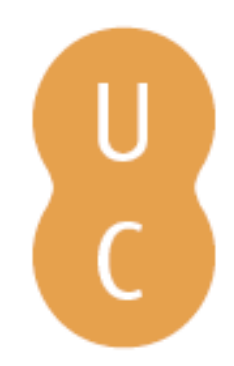

\title{
nombalina
}

\section{Analysis of the effectiveness of fire detection systems in different dimensions}

Autor(es): Restas, Agoston

Publicado por: Imprensa da Universidade de Coimbra

URL

persistente:

URI:http://hdl.handle.net/10316.2/34312

DOI:

DOI:http://dx.doi.org/10.14195/978-989-26-0884-6_145

Accessed : $\quad$ 26-Apr-2023 00:39:48

A navegação consulta e descarregamento dos títulos inseridos nas Bibliotecas Digitais UC Digitalis, UC Pombalina e UC Impactum, pressupõem a aceitação plena e sem reservas dos Termos e Condições de Uso destas Bibliotecas Digitais, disponíveis em https://digitalis.uc.pt/pt-pt/termos.

Conforme exposto nos referidos Termos e Condições de Uso, o descarregamento de títulos de acesso restrito requer uma licença válida de autorização devendo o utilizador aceder ao(s) documento(s) a partir de um endereço de IP da instituição detentora da supramencionada licença.

Ao utilizador é apenas permitido o descarregamento para uso pessoal, pelo que o emprego do(s) título(s) descarregado(s) para outro fim, designadamente comercial, carece de autorização do respetivo autor ou editor da obra.

Na medida em que todas as obras da UC Digitalis se encontram protegidas pelo Código do Direito de Autor e Direitos Conexos e demais legislação aplicável, toda a cópia, parcial ou total, deste documento, nos casos em que é legalmente admitida, deverá conter ou fazer-se acompanhar por este aviso.

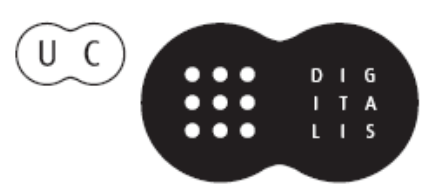




\section{ADVANCES IN}

Forest Fire

\section{RESEARCH}

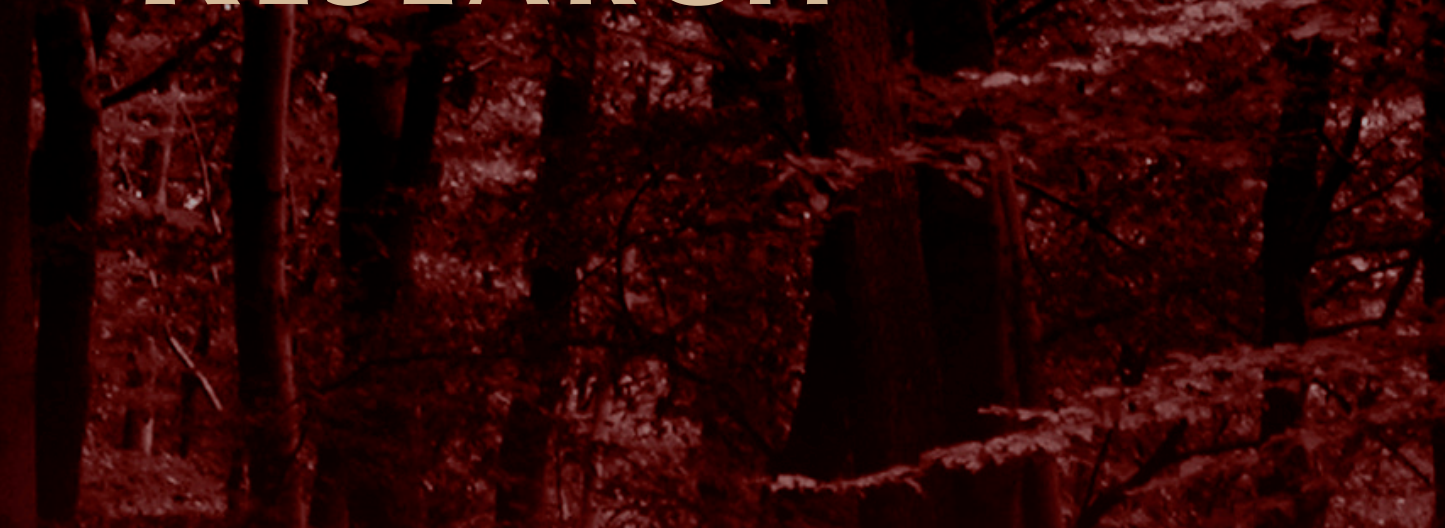

\section{DOMINGOS XAVIER VIEGAS}

\section{EDITOR}




\title{
Analysis of the effectiveness of fire detection systems in different dimensions
}

\author{
Agoston Restas \\ National University of Public Service, Budapest, Hungary, Restas.Agoston@uni-nke.hu
}

\begin{abstract}
Introduction: One of the key elements of the cheap but effective fire suppression is early fire detection and quick initial response. There are many ways of fire detection; in many cases taking an overview of the effectiveness is not useless. Methods: Firstly paper shows the basic principles of the economical effectiveness of the fire management. Afterwards, research turns to the different dimensions and basically counts with aerial flight patrol. Looking at the monitored forest as a flat area gives a 2 dimension analysis but as an articulated area gives a 3 dimension analysis. If research counts with the time scale, meaning the way weather condition changes, it gives a 4 dimension analysis. Results and discussion: Research says in the 2 dimension model the aerial flight patrol cannot be effective, a tower based fire detection system is required.

In case of 3 dimensions model the balance between the methods of aerial flight patrol or the tower based fire detection system depends on feature and rate of the area articulation. The 4 dimensions analysis says that the balance between the methods of aerial flight patrol or the tower based fire detection system can correlate to the fire weather index.
\end{abstract}

Keywords: aerial patrol, UAS application, tower based fire detection system, dimension analysis

\section{Introduction}

One of the key elements of the cheap but effective fire suppression is early fire detection and quick initial response. There are many ways of solutions for the fire detection, such as satellite in orbital equipped with special sensors, manned or unmanned aerial (UAV) flight patrol at different altitude, many kinds of tower based automatic fire detection systems, or mobile human surveillance. Each of them has operation costs, in many cases not negligible, therefore taking an overview of the effectiveness is not useless.

Satellite can be a very effective tool for fire detection but there are some problems with the application. Satellites at geostationary can monitor huge areas but the distance is too far from the Earth to detect hot spots in small size. Sensors with higher resolution could help to detect smaller size fire but there are other problems, like higher price or more false alarms (Pennypacker, 2013). Satellite with closer orbit than geostationary can be also a nice solution but keeping the distance from the Earth requires higher speed meaning that the same area can be monitored cyclically (Giglio at al., 2008). In this case we can count a monitored time and a blind time; latest means that area is not monitored continuously (Restas, 2012). This satellite can be a good solution at huge forested areas such as North and South America, Africa or Siberia.

Human surveillance is also a kind of fire detection method, however the effectiveness is many cases accidental. Closing out the human beings measuring the effectiveness of the human surveillance is more or less similar to tower based fire detection systems. Assuming continuous monitoring and taking into account the horizontal position of the "sensor" to the fire human surveillance can mean the one, on satellite installed sensor the other wings as extremes in the range of different fire detection solutions. All method mentioned above belongs to strategic solutions for hot spot detection however at the beginning of the intervention managers also require tactical solutions. It can mean horizontal observation from the ground or human with special technical equipment like fire truck or UAS. 


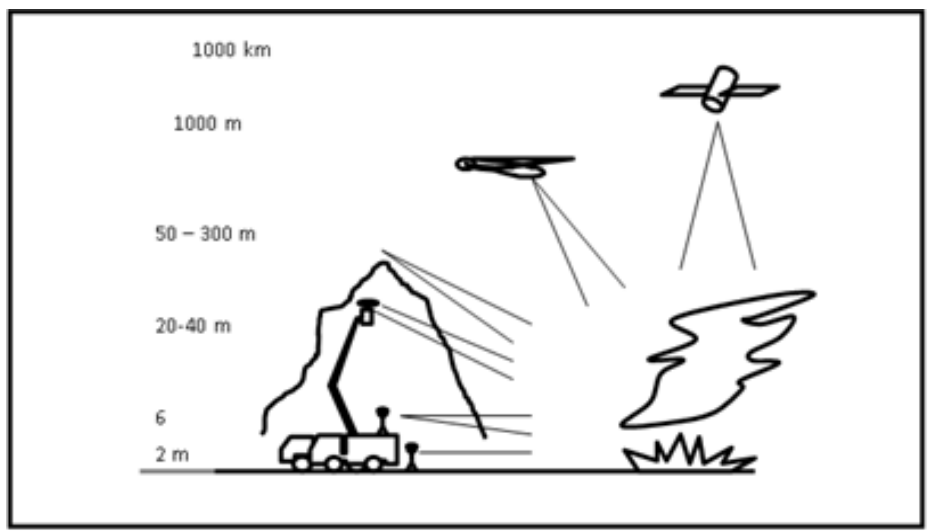

Figure 1. Different solutions for fire detection: from human on ground to on satellite installed sensors

\section{Damage - time function analysis}

When anybody assesses efficiency, it is usually the return on investment and the period of time required for such returns to be realized that we take into account. The concept of efficiency is applicable to firefighting as well, but the way it is applied differs from the traditional interpretation mentioned above. In the case of firefighting and other interventions, efficiency is measured either by the quantity of value saved or by the actual damage, which, of course, should be as small as possible. The value of forest is not homogenous; it depends on variety, age, quality, etc. But forests have not only economical but a social, biological, goodwill, etc. value as well. The goodwill value is much higher than the simply economic value. It applies even more to national parks. Despite this statement this method basically takes into account only the economic value.

The value of saved forest is also not homogenous, neither in time nor in field. Usually it doesn't take into account the total price of the forest. Destruction depends on the age of the forest, the type of the trees, the combustible materials and weather parameters. They are separated not in a discrete value but a complex continuities function.

On the other hand, there are years when the risk is very high, the value of destruction is extreme and in other years much less. Let us look at this curve in the case of a forest fire. The damage-time function gives an exponential curve that diverges to infinity.

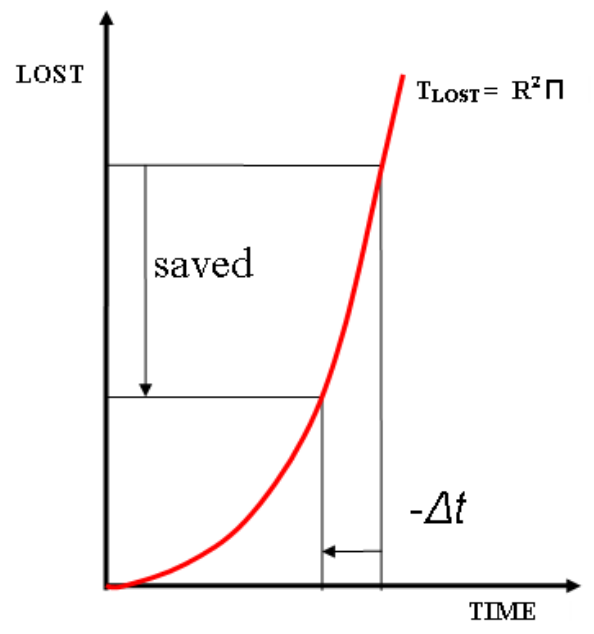

Figure 2. Damage-time function. Basic shape at uncontrolled forest fire 
It is easy to recognise if for any period $\Delta t$ is reduced, the area burnt and thereby the damage caused is reduced exponentially. The smaller the area affected by the fire, the smaller the quantity of resources to extinguish it.

\section{Aerial patrol for hot spot detection $-\mathbf{2}$ dimensions analysis}

\subsection{Basic elements of the effectiveness}

The basic assumption is that by using aerial patrol the fire service can save forest of more value than without it. The economic efficiency will materialize if the saved forest is more than the all expenditure of fire service regarding using aerial surveillance. At the strategical level, author means a bigger scale, let's say at a government level, we have to take into account all the expenditure of aerial surveillance and all the saved forest of the country.

Aerial patrol can detect hot spots very quickly and it is able to give the first fire report to fire brigades; it can reduce the time of first attack.

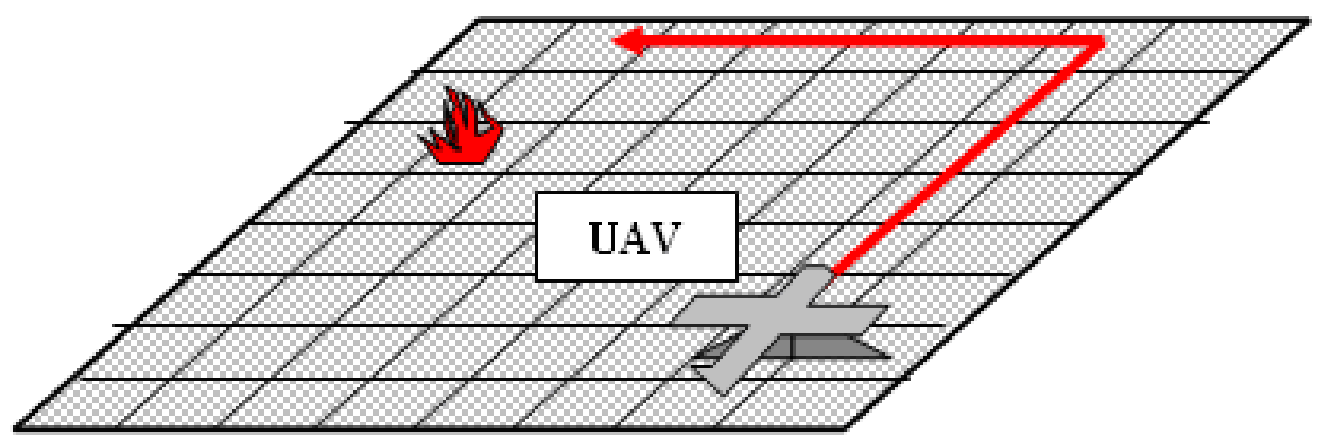

Figure 3. Aerial surveillance e.g. using UAV for hot spot detection

For hot spot detection spotter makes a patrol following the pre-programmed flight path usually as routine task. Obviously, the average delay of the aerial fire report must be less than the average delay of the civil report. This condition is necessary even if not sufficient for satisfying the requirements of economic efficiency of aerial surveillance, in this example UAV flight.

From the ignition (fire starts) till the aerial based fire report takes different time depending on the position of the UAV and the position of the ignited fire crossed by planned flight path. Obviously large number of fire detection (statistical data base) gives for the time of average fire report as a half time of the UAV patrol time. This statement can be accepted also by logical conclusion.

$$
\begin{aligned}
& \bar{t}_{U A V_{-} \text {report }}=\frac{1}{2} t_{U A V_{-} \text {patrol }} \\
& \bar{t}_{U A V_{-} \text {report }}<\bar{t}_{\text {Civil_report }}
\end{aligned}
$$

- $t_{U A V}$ patrol - full time of a flight patrol, made by UAV;

- $\quad t_{U A V}$ report - average time of fire report given by UAV, making fire patrol;

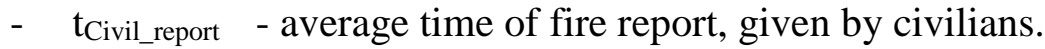

The other criteria for satisfying the economically efficiency is that based on aerial surveillance (e.g. UAV use) fire service must save forest of more value than the costs of the surveillance (aerial patrol). 
A quick fire report results in quick answer; short uncontrolled fire means less damages but more saved value.

If the intervention starts very soon after ignition, the savings will come not just from the saved forest but also from a shorter use of the special equipment required to suppress the fire (figure 4).

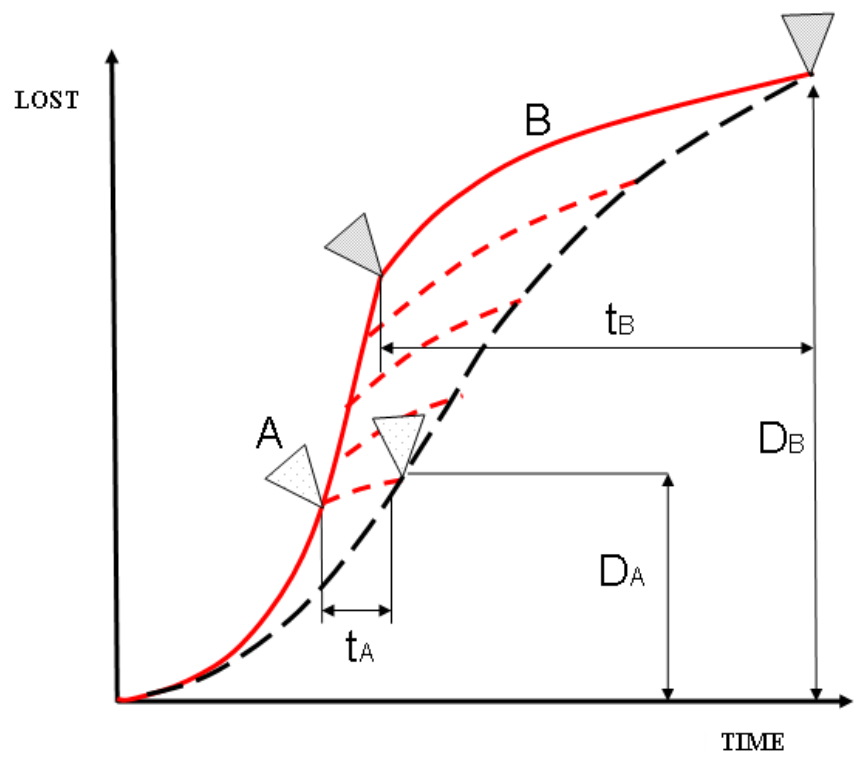

Figure 4. Structure of damage - time functions taking into account the quick fire report

Modelling the extinguishing of the fire by the damage - time functions the beginning of the response will break the fire curve (figure $2 \rightarrow$ figure 4 ). The intensity and the length of the modified fire curve will depend on the time between the ignition and the beginning of the response. In case of A the time is shorter than in case of B therefore in case of A the intensity is lower and the length is shorter of the modified fire curve than in case of B (figure 4). The response in case of A results in lower damage (lost) and shorter time of intervention; this latest one results also in lower costs of the intervention. The shorter the time is between the ignition and the beginning of the response, the lower the intensity and the shorter the modified fire curve is. The above criteria can be expressed also by the next formulas:

$$
\begin{gathered}
S \Rightarrow D\left[\bar{t}_{\text {Civil_report }}-\frac{1}{2} t_{U A V_{-} \text {patrol }}\right]>\Sigma C_{U A V_{-} \text {patrol }} \\
\int_{\frac{1}{2} t_{\text {UAV_patrol }}}^{\bar{t}_{\text {Civil_report }}} D>\Sigma C_{U A V_{-} \text {patrol }}
\end{gathered}
$$

- S (D) - damages between the average term of civil report and aerial report;

- A - characteristic of suppression using UAV support;

- B - characteristic of suppression without UAV support.

Till the above formulas are valid the criterion of the economically based efficiency is satisfied at UAV patrol based fire management. 


\subsection{Moving to higher effectiveness - flight speed analysis}

Since the efficiency obviously depends on the difference of the civil based and aerial supplied report's time, the question spontaneously arises, how can we make longer term between these reports? Based on the above formulas the delay of civil report is relatively stable, while the aerial based hot spot detection depends mainly on flight regimes. Therefore, making the aerial based hot spot detection more efficient we must face fly parameters. Logically we can test the flight speed, the altitude and the visual or camera (UAV) focus. During the analysis idealistic circumstances are supposed: there is no wind, it counts just with one hot spot, price of the technical elements, like camera does not change, weather does not limit the visibility, area is flat, etc. This latest one, the flat area means that we monitor 2 dimensions extension.

The purpose of reducing the average detection time requires the flight speed rise. With this process the flight path will not change but the time of aerial patrol will reduce. In case of a $24 \mathrm{~km} \times 24 \mathrm{~km}$ area, with about a $180 \mathrm{kmh}^{-1}$ flight speed and about a $3 \mathrm{~km}$ x $3 \mathrm{~km}$ monitored (camera) pixel in a moment (e.g. UAV) the monitored time for 1 pixel is 1 minute then 63 minutes are blind; the rate of monitored and blind area is 1:63. Raising the speed the cycle will reduce but the rate of the monitored and blind area will not. The problem is that the flight speed rise is objectively limited.
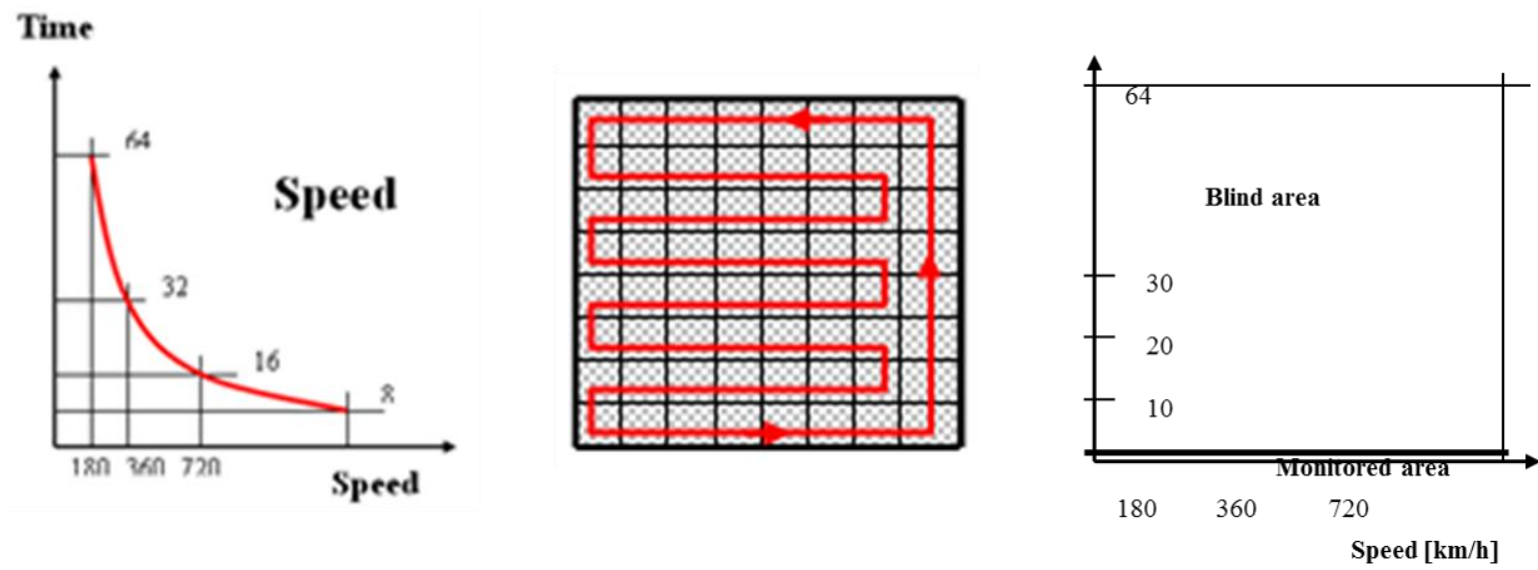

Figure 5-Example for moving towards the higher effectiveness of the fire detection. Raising the flight speed neither the flight path nor the rate of monitored and blind area do not change

\subsection{Moving to higher effectiveness - camera focus and altitude analysis}

The analyses of camera focus and altitude gives a little bit different results. Rising the altitude the on board installed camera monitors larger area (pixel). If the frame of the supervised area remains but the monitored pixel is larger than earlier, it means that the flight path can change; obviously it will be shorter. The flight path will move to the center of the area. Step by step continuing this process it reaches the end values when the flight path will concentrate at the middle point of the supervised area. It means our aerial means hangs on the central point of the area without flight speed! Logically the end value doesn't require the manned or unmanned flight; in this case a tower based camera system can be an alternative solution with the same effectiveness. 

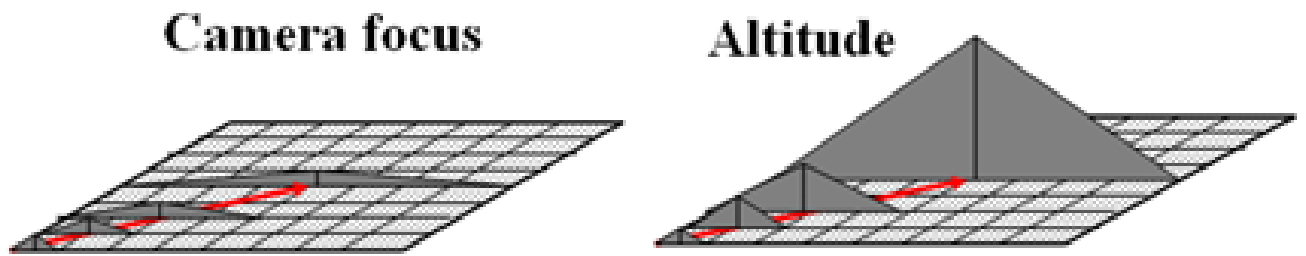

\section{Changing flight patrol}
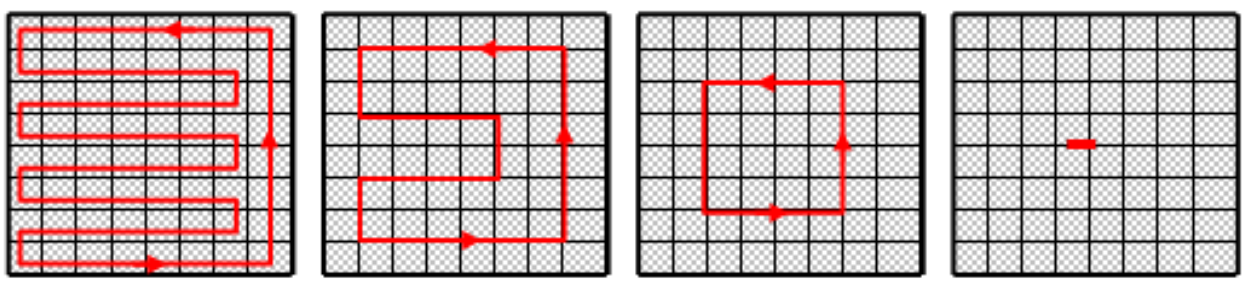

Figure 6- Example for moving towards the higher effectiveness of the fire detection. Raising the angle of camera focus or the altitude the flight path changes; it moves to the centre of the monitored area

Without deeper explanation it can be accepted the analysis of camera focus with similar way as above gives the same results. In this case there is no or insignificant difference between the altitude of aerial "surveillance" -hanging on the center point of the area - and tower based fire detection system.

In both cases the rate of the monitored and blind area also changes; it drastically turns beneficially. At the end of the process the rate is 1:0; which means all area is monitored continuously. Even if the effectiveness of both systems - aerial surveillance and tower based fire detection system - can be similar that is not sure in case of efficiency. If all the costs of using tower based fire detection system and the aerial surveillance are similar the efficiencies are also similar. In the assumptions we took into account same technical parameters - it means camera installed on board or tower too - therefore, the difference of the efficiency generates from the all costs of using the systems. This is true in case of UAV use too, even if it is supposed to be a cheaper solution than manned aircraft. In this case the tipping point - meaning the balanced costs - can be lower.
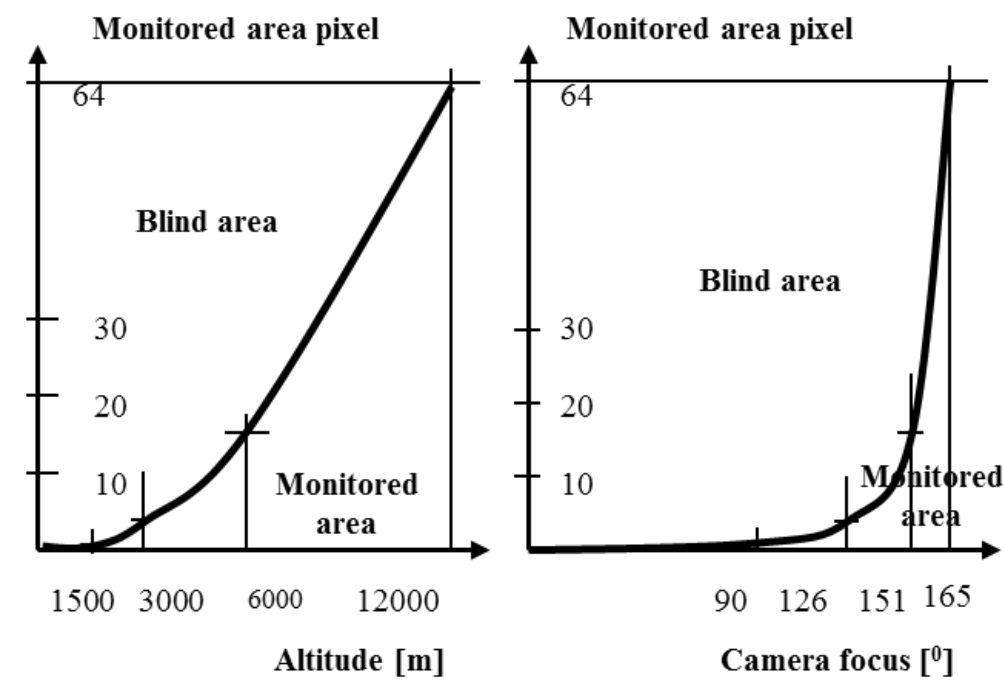

Figure 7-The rate of the monitored and blind area changes drastically positive 


\section{Geographically high articulated area $-\mathbf{3}$ dimensions analysis}

Based on the above using tower based fire detection system in case of flat area -2 dimensions extension - is more effective. The question is that in what or when the higher efficiency can be limited. As a first step, author extended flat -2 dimensions - area to geographically high articulated -3 dimensions - area.

In case of flat area tower based fire detection system can detect hot spots by direct way; it means there is no natural or manmade barrier to "see" the hot spots by the camera or sensor. In case of articulated areas the way for fire detection can be different. If the ignition is at the valley or at the bottom of the slope it can be in shadow of the hills, therefore, tower based fire detection system can detect fire in many cases only by indirect way; it means fire is in the shadow of the hill, camera or sensor cannot detect the fire but the smoke column or plum of it.

Naturally the smoke column in indirect way can be detected later than fire in direct way. Depending on different circumstances - wind power and direction, inversion, fire intensity, rate and way of the articulation, etc. - the detection of smoke column can delay significantly. It means that not just the effectiveness of the tower based fire detection system reduces but also the efficiency of it. The rate of reduction naturally depends on the rate and way of articulation; this is a circumstance that does not change in time. In case of high articulation reduction of effectiveness is surely higher; however, the rate of correlation between them requires advanced research. Moreover, the way of articulation is also important.
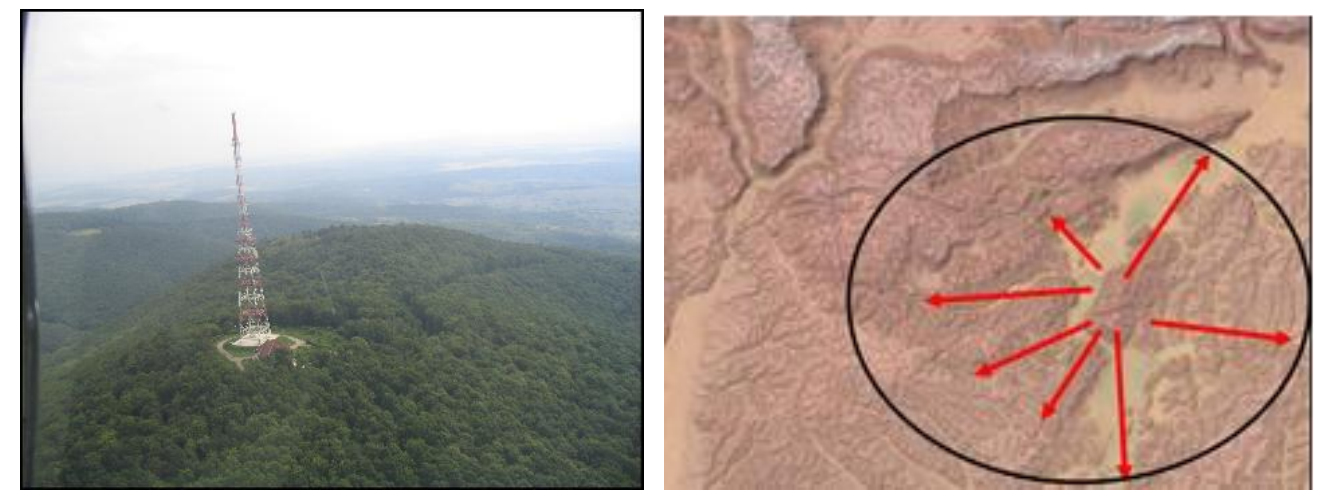

Figure 8-Example for a geographically good positioned tower based fire detection system. Aggtelek National Park - Szendro Fire Department, Hungary, Installation: 2005

There is an example where tower based fire detection system was installed in such an advantageous way that the valley's position looks like radiation spread from it (Restas, 2006). Positioning this kind of system is very important; it basically determines its potential of both effectiveness and efficiency. Good positioning - even if just a limited way, but - can reduce the shadow effect of hills.

When positioning of the system cannot be advantageous but the area is high articulated the rate of direct detection and indirect detection can be also very bad. The smoke emission from the valley stand ignited fire can be detected only with such delay so the advantages of low yearly costs evaporate.

Obviously the mission costs of aerial surveillance do not depend or just to a limited extent on the rate of area articulation. On the other hand, during flight patrol the shadow effect of hills can be relevant only for that pixel where the aircraft flies above. Naturally this effect is much lower in this case than in case of tower based fire detection system. Since the effectiveness and efficiency correlate to each other, the higher costs of aerial surveillance can be balanced by the lower effectiveness of the tower based system. It can be explained by other words too; the rate of catching hot spots in time by aerial surveillance is higher than in case of tower based system. The disadvantageous rate of monitored and 
blind area is balanced by higher rate of quick fire report regarding shadow area. The above criterion can be expressed by formula (1) and (5) too.
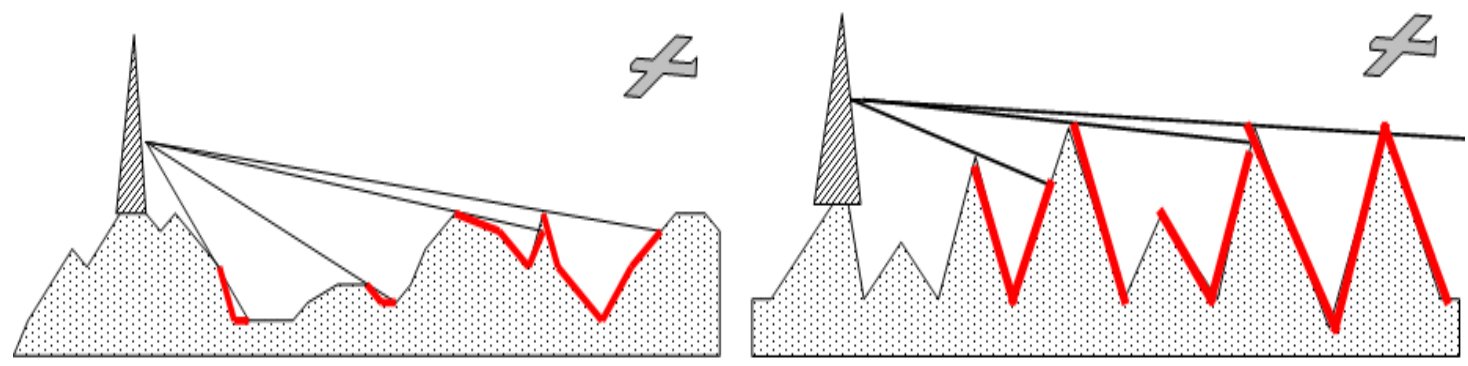

Figure 9- High articulated area: direct detection versus indirect detection (red colored slopes).

Aerial surveillance versus tower based fire detection system

$$
\begin{aligned}
& \bar{t}_{U A V_{-} \text {report }}=\frac{1}{2} t_{U A V_{-} \text {patrol }} \\
& \bar{t}_{U A V_{-} \text {report }}<\bar{t}_{\text {delay_tower_report }}
\end{aligned}
$$

- $\quad t_{\text {delay_tower_report }}$-average delay of fire report, given by tower based fire detection system.

As the formulas (1) and (3) are logically same at time factor, formula (3) and (6) also have logical similarity in costs factor.

$$
S \Rightarrow D\left[\bar{t}_{\text {delay_tower_report }}-\frac{1}{2} t_{U A V_{-} \text {patrol }}\right]>\Sigma C_{U A V_{-} \text {patrol }}
$$

It means also that it must satisfy other basic criterion too, as quicker average fire report than report of civilians. Till the above formulas are valid the criterion of the economically based efficiency is satisfied at aerial surveillance versus tower based fire detection system.

\section{Extremely High Fire Weather Index - 4 dimensions analysis}

Analysis above focused on physical extension of the given area; 2 dimensions counted as flat area, 3 dimensions as articulated area. In any case, there is no difference in time range; it takes into account time range as standard condition, however areas are threatened by fire risk usually cyclically so-called fire seasons. If the fire risk is cyclic, the question arises spontaneously, can it be even cyclic or not monitoring the area? If we take into account the cyclic - fire seasons - as time factor, it can mean as 4 dimensions analysis.

It is known, fire seasons strongly correlate to weather conditions; for measuring it different type of index - fire weather index (FWI) - were created, e.g. Canada: McArthur FWI (Dowdy at al., 2010), Germany: Waldbrandgefahrenindex WBI (König, 2007). That is obvious, area monitoring is the more required the higher the fire risk; in this case probability of matching hot spots is higher, which is shown by FWI. Therefore, it is practical to find correlation between FWI and effectiveness of fire detection. 

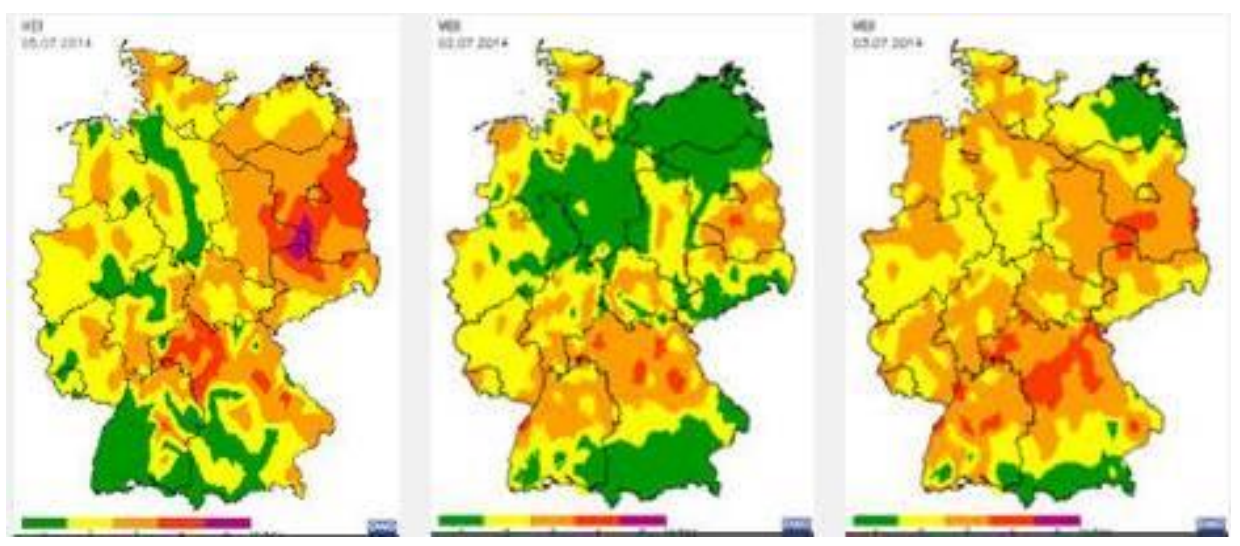

Figure 10. Examples for Waldbrandgefahrenindex, July 2014, Germany

Following the correlation, FWI based planning of applied system for fire detection does not require area monitoring all year round. This condition is not relevant for tower based fire detection system because its installation fix and it is able to work during all year. It means we need count with its all year costs. In case of aerial surveillance we have to count with costs only for that period when it is occasionally demanded.

There are some options for analyzing the efficiency: areas extension can be taken as 2 dimensions or 3 dimensions, however the essence of both results must be similar.

In case of same effectiveness - the average rate of fire detection is equal - the cheaper solution takes the higher efficiency, however this possibility has low chance. The other situation is when there are differences between both the average rates of the fire detection and the costs of using the different systems; obviously the higher costs of the aerial fire detection are suspected. In case of same efficiency the higher costs of aerial fire detection must be balanced by the higher rate of matching hot spots; it is the tipping point. Above this threshold - taking into account fix price for the flight hour - aerial fire detection is more efficient, otherwise not.

Otherwise, if there is difference in match of hot spot detection we have to calculate the rate of the difference between the saved forest and costs. In basic situation the criterion can be expressed by the next formula:

$$
\Sigma C_{U A V_{-} \text {occasionally }}<\Sigma C_{\text {Tower_yearly_costs }_{\text {_t }}}
$$

$$
\begin{array}{ll}
\sum \mathrm{C}_{\mathrm{UAV}} \text { occasionally } & \text { - occasional costs of UAV, used it at extremely high FWI; } \\
\sum \mathrm{C}_{\text {Tower_yearly_costs }} & \text { - yearly costs of the tower based fire detection system. }
\end{array}
$$

Till the above formula is valid the criterion of the economically based efficiency is satisfied at extremely high FWI term.

It can be seen, this latest analysis contains the most vulnerable elements. Therefore, this paper just shows some directions for further research, exact definition of the tipping point as well as determines the correlation between the higher rate of matching hot spots and the efficiency requiring more study.

\section{Summarizing}

There is no doubt one of the key elements of the cheap but effective fire suppression is the early fire detection and quick initial response. There are many solutions for the fire detection however in many cases taking an overview of the effectiveness is not useless.

This paper firstly described the basic principles of the economical effectiveness of the fire management. Afterwards, research turned to the different dimensions and basically counts with aerial 
flight patrol. Looking at the monitored forest as a flat area, it gives 2 dimensions analysis but as an articulated area it gives 3 dimensions analysis. Research counted also with the time scale, meaning that weather conditions can change; it gave the 4 dimensions analysis.

Based on the research in the 2 dimension model the aerial flight patrol cannot be effective, a tower based fire detection system is required. In case of 3 dimensions model the balance between the methods of aerial flight patrol or the tower based fire detection system depends on feature and rate of the area articulation. The 4 dimensions analysis says that the balance between the methods of aerial flight patrol or the tower based fire detection system can correlate to the fire weather index.

Research pointed out that applied analysis contains many vulnerable elements. Therefore, this paper just shows some directions for further research, exact definition of the tipping point as well as determines the correlation between the higher rate of matching hot spots and the efficiency requiring more study.

\section{References}

Dowdy, A.D., Graham A. Mills G.A., Finkele1, K., Groot, W.: Index sensitivity analysis applied to the Canadian Forest Fire Weather Index and the McArthur Forest Fire Danger Index; Meteorological Applications, 17 (3), pp. 298-312, September 2010 DOI: 10.1002/met.170

Giglio, L., Csiszar, I., Restas, A., Morisette, J.T., Schroeder, W., Morton, D., Justice, C.O.: Active fire detection and Characterization with the Advanced Spaceborne Thermal Emission and Reflection Radiometer (ASTER) Elsevier Science, Remote Sensing of Environment 112 (2008) 3055-3063

König, H.C.: Waldbrandschutz. Kompendium für Forst und Feuerwehr. Edition GefahrenAbwehr; Supplement (Band 1). Fachverlag Grimm, Berlin 2007, 197 S., ISBN 978-3-940286-01-7 oder ISBN 3-940286-01-X

Pennypacker, C.R., Jakubowski, M.K., Kelly, M., Lampton, M., Schmidt, C., Stephens, S., and Tripp, R.: FUEGO - Fire Urgency Estimator in Geosynchronous Orbit - A Proposed Early-Warning Fire Detection System; Remote Sensing, 2013 5(10) ISSN 2072-4292

Restas, A.: Integrated Vegetation Fire Management at Aggtelek National Park. Wildfire Management Program from Hungary; International 5th ICFFR, Conference on Forest Fire Research; Coimbra, Portugal, 2006

Restas, A.: An Approach for Measuring the Economic Efficiency of UAV Applications at Forest Fires Helping Decision Makers; AUVSI 2012: The First International Conference on Unmanned Systems in Israel. Tel Aviv, Israel, 2012. 